Mw. Dr. A.S. Glas

Dr. J.P.M. Sedelaar

$P$. van de Woestijne

Het urologie formularium 
Onder redactie van:

Mw. Dr. A.S. Glas

Dr. J.P.M. Sedelaar

$P$. van de Woestijne

\section{Het urologie formularium}

tweede, herziene druk

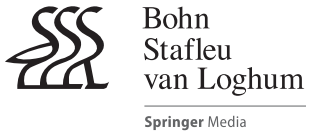




\section{ISBN 978-90-368-0627-5}

(C) Bohn Stafleu van Loghum, onderdeel van Springer Media BV, 2015

Alle rechten voorbehouden. Niets uit deze uitgave mag worden verveelvoudigd, opgeslagen in een geautomatiseerd gegevensbestand, of openbaar gemaakt, in enige vorm of op enige wijze, hetzij elektronisch, mechanisch, door fotokopieën of opnamen, hetzij op enige andere manier, zonder voorafgaande schriftelijke toestemming van de uitgever.

Voor zover het maken van kopieën uit deze uitgave is toegestaan op grond van artikel 16b Auteurswet jo het Besluit van 20 juni 1974, Stb. 351, zoals gewijzigd bij het Besluit van 23 augustus 1985, Stb. 471 en artikel 17 Auteurswet, dient men de daarvoor wettelijk verschuldigde vergoedingen te voldoen aan de Stichting Reprorecht (Postbus 3060, 2130 KB Hoofddorp). Voor het overnemen van (een) gedeelte(n) uit deze uitgave in bloemlezingen, readers en andere compilatiewerken (artikel 16 Auteurswet) dient men zich tot de uitgever te wenden.

Samensteller(s) en uitgever zijn zich volledig bewust van hun taak een betrouwbare uitgave te verzorgen. Niettemin kunnen zij geen aansprakelijkheid aanvaarden voor drukfouten en andere onjuistheden die eventueel in deze uitgave voorkomen.

Ontwerp omslag: Studio Bassa, Culemborg

Automatische opmaak: Pre Press Media Groep, Zeist

Bohn Stafleu van Loghum

Het Spoor 2

Postbus 246

3990 GA Houten

www.bsl.nl 


\section{Voorwoord}

In uw handen ligt de eerste editie van Het Urologie Formularium, een praktische leidraad. In dit formularium komen de meest relevante aspecten van de urologie aan de orde. Het doel van Het Urologie Formularium is de ruimte te dichten tussen de richtlijnen van het NHG en de Nederlandse Vereniging voor Urologie (NVU) en het Compendium Urologie, dat in 2008 is uitgegeven door de NVU en aan alle huisartsen is verstrekt.

Behalve een praktisch handvat geven we $\mathrm{u}$ ook informatie ter verdieping van relevante urologische problematiek. Zo heeft de PSA-bepaling zijn eigen hoofdstuk. Een ander doel is $\mathrm{u}$ inzicht te geven in het traject bij de uroloog, om zo de patiënt beter voor te kunnen bereiden op een bezoek aan de uroloog of een urologische behandeling.

Het formularium is in tweeën verdeeld. Het eerste deel bevat hoofdstukken geschreven vanuit de symptomatologie, bijvoorbeeld het hoofdstuk over hematurie. Het tweede deel omvat hoofdstukken geschreven vanuit het vastgestelde ziektebeeld, bijvoorbeeld blaaskanker.

We hebben als redactie vooral jonge urologen, die vanwege hun onderzoek een goed overzicht hebben van het betreffende onderwerp, de kans gegeven zich op deze manier te profileren.

We willen alle auteurs bedanken voor hun geweldige inzet; het is een mooi overzicht geworden! Dit is de eerste editie, we gaan ervan uit dat er nog vele zullen volgen. Daarom vernemen we graag uw opmerkingen of andere suggesties ter verbetering. 
Voor nu hopen we dat $\mathrm{u}$ dit formularium goed kunt gebruiken voor uw patiënt.

\section{Bij de tweede editie}

Met de tweede editie heeft Het Urologie Formularium een aantal wijzigingen ondergaan. Zo is bijvoorbeeld hoofdstuk 9. Prostaatcarcinoom, aangepast aan de nieuwe ontwikkelingen in het gebruik van MRI bij prostaatkankerdiagnostiek. Deze editie geeft u ook een up-to-date overzicht van de huidige medicijnen die op de markt zijn ter behandeling van urologische problemen. We hopen wederom dat $\mathrm{u}$ dit formularium goed kunt gebruiken in uw praktijk. 


\section{Redactie en auteurs}

\section{Redacteuren}

Mw. dr. A.S. Glas

Uroloog, Zaans Medisch Centrum, Zaandam

Dr. J.P.M. Sedelaar

Uroloog, Radboudumc, Nijmegen

P. van de Woestijne

Huisarts, Deil

\section{Medewerkers}

Dr. F.C.H. d'Ancona

Uroloog, Radboudumc, Nijmegen

Mw. drs. C.P.E. Asselbergs

Uroloog, Academisch Medisch Centrum, Amsterdam

Dr. M.M. Barendrecht

Uroloog, UMC Utrecht en Centraal Militair Hospitaal, Utrecht

Dr. J.J.H. Beck

Uroloog - medisch seksuoloog, FEBU-FECSM, Zuwe Hofpoort, Woerden en St. Antonius, Utrecht-Nieuwegein

Mw. dr. A.M.J. Bootsma

Uroloog, Scheper Ziekenhuis, Emmen

Mw. dr. M. Dinkelman-Smit

Uroloog, Erasmus Medisch Centrum, Rotterdam

Mw. drs. L.C. Gerbrandy-Schreuders

Uroloog, AMC \& Bergman Vrouwenzorg

Mw. dr. A.S. Glas

Uroloog, Zaans Medisch Centrum, Zaandam

Mw. dr. K. D'Hauwers

Uroloog, Radboudumc, Nijmegen 
VIII Redactie en auteurs

Dr. P.J.M. Kil

Uroloog, Elisabeth Ziekenhuis, Tilburg

Dr. T.A.T. Marcelissen

Uroloog i.o., Atrium MC, Heerlen

Dr. R.P. Meijer

Uroloog, Universitair Medisch Centrum, Utrecht

Mw. M.L. Mensink

Uroloog, Haga Ziekenhuis, Den Haag

Mw. dr. I.M. van Oort

Uroloog, Radboudumc, Nijmegen

Prof. dr. Th.M. de Reijke

Uroloog, Academisch Medisch Centrum, Amsterdam

Mw. drs F. van Rey

Uroloog, Meander Medisch Centrum, Amersfoort

Dr. B.W.G. van Rhijn

Uroloog, Nederlands Kanker Instituut, Amsterdam

Mw. M.G. Rombouts

Bekkenfysiotherapeut, Nijmegen

Dr. P.F.W.M. Rosier

Arts functionele urologie, Universitair Medisch Centrum, Utrecht

Prof. dr. J.J.M.C.H. de la Rosette

Uroloog, Academisch Medisch Centrum, Amsterdam

Dr. J.P.M. Sedelaar

Uroloog, Radboudumc, Nijmegen

Prof. dr. S. de Wachter

Uroloog, Universitair Ziekenhuis, Antwerpen

Mw. drs. W.C.G. Zonneveld

Uroloog, Leids Universitair Medisch Centrum, Leiden 


\section{Inhoud}

Diagnostiek en beleid bij klachten en testuitslagen

Lower urinary tract symptoms (LUTS) ten gevolge van benigne prostaathyperplasie (BPH)

P.J.M. Kil

Inleiding . .

Diagnostiek

Behandeling

Verwijzen van de patiënt met LUTS voor specialistisch onderzoek

Literatuur

Hematurie

C.P.E. Asselbergs, J.J.M.C.H. de la Rosette en Th.M. de Reijke Inleiding.

Anamnese

Lichamelijk onderzoek

Diagnostiek door de huisarts

Aanvullende diagnostiek door de uroloog

Follow-up bij asymptomatische microscopische hematurie, na negatieve analyse.

Follow-up bij asymptomatische macroscopische hematurie, na negatieve analyse $\ldots \ldots \ldots \ldots \ldots \ldots \ldots \ldots \ldots . \quad 30$

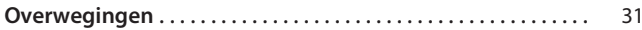

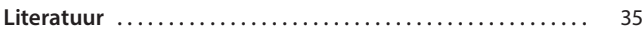

M.L. Mensink

Inleiding.

Torsio testis

Trauma testis 
X Inhoud

3.7 Spermatokèle/epididymiscyste $\ldots \ldots \ldots \ldots \ldots \ldots \ldots \ldots, 43$

Literatuur .............................. 44

Afwijkingen van de penis $\ldots \ldots \ldots \ldots \ldots \ldots \ldots \ldots \ldots, 45$

M.L. Mensink

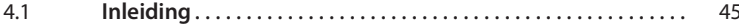

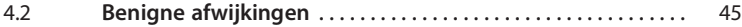

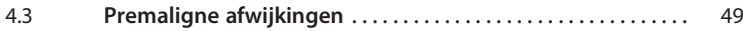

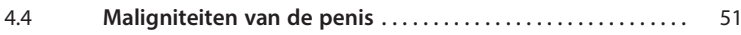

4.5 Virusgerelateerde afwijkingen .................. 52

4.6 Traumatische afwijkingen van de penis ............. 54

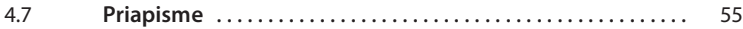

$4.8 \quad$ M. Peyronie ............................... 55

Literatuur ................................... 56

F. van Rey en F.C.H. d'Ancona

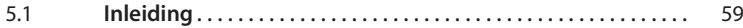

$5.2 \quad$ Niersteenkoliek ............................ 59

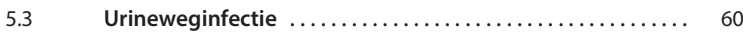

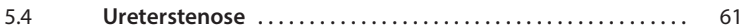

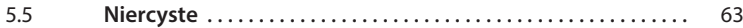

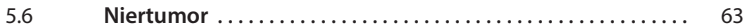

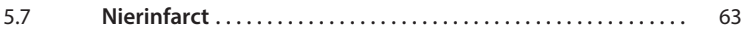

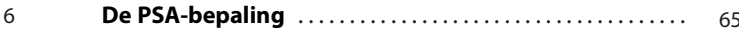

J.P.M. Sedelaar

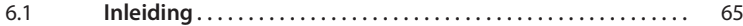

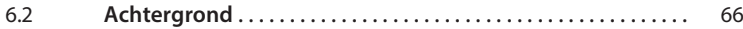

$6.3 \quad$ Wanneer PSA bepalen? $\ldots \ldots \ldots \ldots \ldots \ldots \ldots \ldots \ldots \ldots \ldots \ldots$

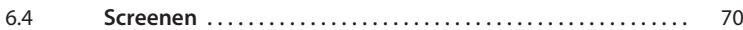

6.5 Samenvatting en aanbeveling ................. 72

Literatuur ................................. 72

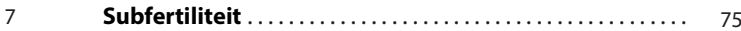

M. Dinkelman-Smit

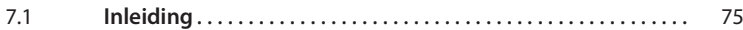

$7.2 \quad$ Afwijkend semenonderzoek ................... 76 


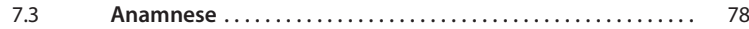

$7.4 \quad$ Lichamelijk onderzoek ....................... 80

7.5 Aanvullende diagnostiek bij afwijkend semenonderzoek . 81

$7.6 \quad$ Behandeling .................................. 85

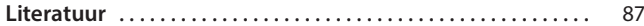

$8 \quad$ Infecties en andere problemen met verblijfskatheters

P.F.W.M. Rosier

$8.1 \quad$ Inleiding $\ldots \ldots \ldots \ldots \ldots \ldots \ldots \ldots \ldots \ldots \ldots \ldots \ldots \ldots \ldots \ldots \ldots, \quad 89$

8.2 Relevante fysiologie: de normale verdediging ......... 91

8.3 Optimale zorg rondom verblijfskatheters ............ 91

8.4 Vermijdbare problemen met verblijfskatheters ........ 94

Literatuur ................................ 100

II Ziektebeelden

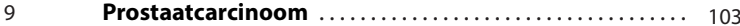

J.P.M. Sedelaar en I.M. van Oort

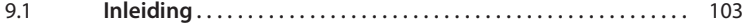

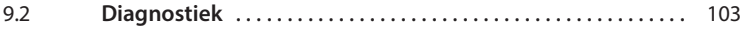

$9.3 \quad$ Behandeling $\ldots \ldots \ldots \ldots \ldots \ldots \ldots \ldots \ldots \ldots \ldots \ldots \ldots \ldots \ldots \ldots \ldots \ldots$

10 Urotheelcelcarcinoom $\ldots \ldots \ldots \ldots \ldots \ldots \ldots \ldots \ldots \ldots \ldots \ldots \ldots \ldots \ldots \ldots$

R.P. Meijer en B.W.G. van Rhijn

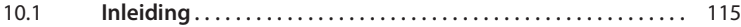

10.2 Indeling urotheelcelcarcinoom $\ldots \ldots \ldots \ldots \ldots \ldots \ldots \ldots, 116$

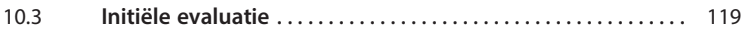

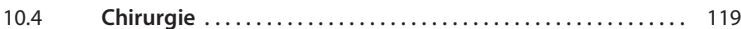

$10.5 \quad$ Follow-up $\ldots \ldots \ldots \ldots \ldots \ldots \ldots \ldots \ldots \ldots \ldots \ldots \ldots \ldots \ldots \ldots \ldots \ldots, 122$

Literatuur ................................. 126

$11 \quad$ Urineweginfecties $\ldots \ldots \ldots \ldots \ldots \ldots \ldots \ldots \ldots \ldots \ldots \ldots \ldots \ldots \ldots \ldots$

A.M.J. Bootsma

$11.1 \quad$ Inleiding $\ldots \ldots \ldots \ldots \ldots \ldots \ldots \ldots \ldots \ldots \ldots \ldots \ldots \ldots \ldots \ldots \ldots \ldots \ldots \ldots \ldots, 127$

11.2 Definities ................................. 128

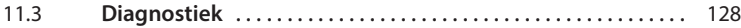

$11.4 \quad$ Behandeling $\ldots \ldots \ldots \ldots \ldots \ldots \ldots \ldots \ldots \ldots \ldots \ldots \ldots \ldots \ldots \ldots \ldots, 132$

$11.5 \quad$ Verwijzing naar de tweede lijn $\ldots \ldots \ldots \ldots \ldots \ldots \ldots \ldots \ldots \ldots$ 
Literatuur ................................ 140

12 Overactieve blaas

S. de Wachter en T. Marcelissen

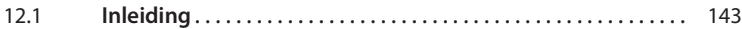

$12.2 \quad$ Aanpassing van leefgewoonten $\ldots \ldots \ldots \ldots \ldots \ldots \ldots \ldots$

$12.3 \quad$ Bekkenbodemtraining en blaastraining ............. 144

$12.4 \quad$ Medicatie ...................................... 145

$12.5 \quad$ Behandeling in de eerste lijn .................. 147

$12.6 \quad$ Gespecialiseerde behandeling ................... 148

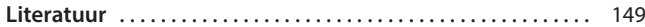

13 Stressincontinentie bij de vrouw $\ldots \ldots \ldots \ldots \ldots \ldots \ldots 151$

L.C. Gerbrandy-Schreuders

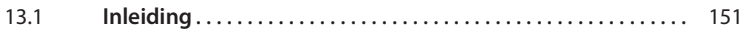

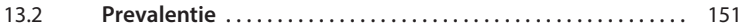

13.3 Fysiologie van het continentiemechanisme .......... 152

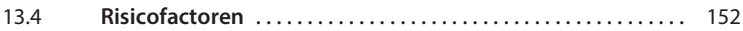

13.5 Anamnese bekkenbodemklachten ............... 153

$13.6 \quad$ Lichamelijk onderzoek ........................ 154

13.7 Aanvullend onderzoek ....................... 156

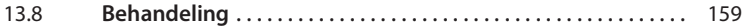

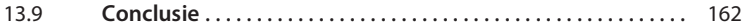

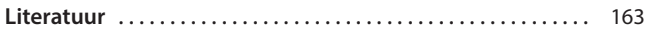

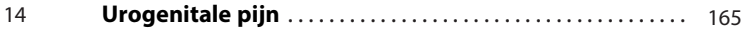

A.S. Glas

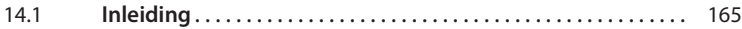

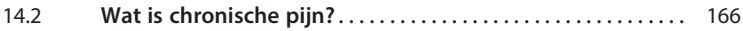

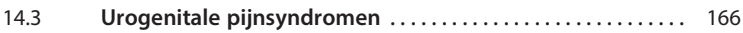

14.4 Diagnostiek door de huisarts .................. 171

14.5 Behandeling die de huisarts kan instellen ........... 172

14.6 Wanneer verwijzen naar de uroloog? .............. 172

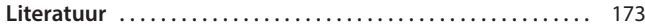




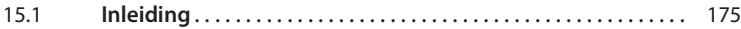

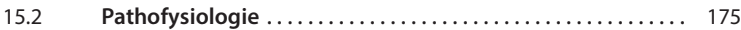

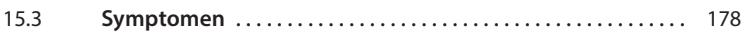

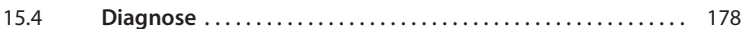

$15.5 \quad$ Behandeling $\ldots \ldots \ldots \ldots \ldots \ldots \ldots \ldots \ldots \ldots \ldots \ldots \ldots \ldots \ldots \ldots \ldots \ldots, 179$

Literatuur ................................ 181

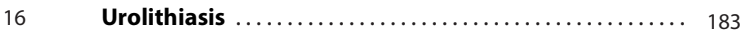

W.C.G. Zonneveld

$16.1 \quad$ Inleiding $\ldots \ldots \ldots \ldots \ldots \ldots \ldots \ldots \ldots \ldots \ldots \ldots \ldots \ldots \ldots \ldots \ldots, 183$

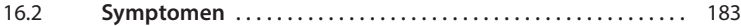

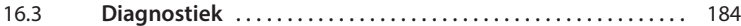

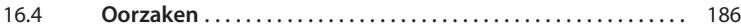

$16.5 \quad$ Behandeling $\ldots \ldots \ldots \ldots \ldots \ldots \ldots \ldots \ldots \ldots \ldots \ldots \ldots \ldots \ldots \ldots \ldots \ldots$

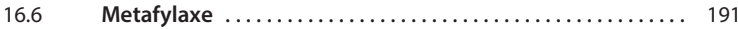

Literatuur .............................. 193

$17 \quad$ Seksuele disfuncties .......................... 195

J.J.H. Beck en K. d'Hauwers

$17.1 \quad$ Vroegtijdige zaadlozing ....................... 195

17.2 Vroegtijdige zaadlozing en comorbide erectiele disfunctie ........................................ 201

17.3 Erectiele disfunctie $\ldots \ldots \ldots \ldots \ldots \ldots \ldots \ldots \ldots \ldots \ldots, 202$

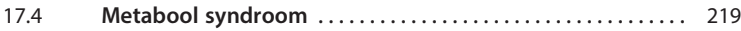

Literatuur ............................... 223

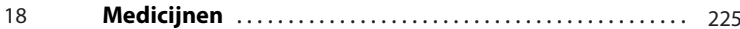

M.M. Barendrecht

$18.1 \quad$ Alfablokkers $\ldots \ldots \ldots \ldots \ldots \ldots \ldots \ldots \ldots \ldots \ldots \ldots \ldots \ldots \ldots \ldots \ldots \ldots \ldots, 225$

18.2 Anticholinergica en bèta-3-agonisten $\ldots \ldots \ldots \ldots \ldots \ldots .228$

18.3 5-alfareductaseremmers (5AR-remmers) en gecombineerde alfablokker/5AR-remmer ................ 230

$18.4 \quad$ LHRH-agonisten en -antagonisten $\ldots \ldots \ldots \ldots \ldots \ldots \ldots .233$

18.5 Fosfodi-esterase-5-remmers (PDE-5-remmers) . . . . . . 235

$18.6 \quad$ Testosteron $\ldots \ldots \ldots \ldots \ldots \ldots \ldots \ldots \ldots \ldots \ldots \ldots \ldots \ldots \ldots \ldots \ldots \ldots \ldots \ldots \ldots, 238$ 
XIV Inhoud

\section{Bijlagen}

Geneesmiddelenoverzicht ................ 242

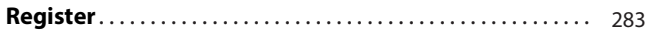

